\title{
Life Enhancing Activities for Family Caregivers of people with dementia: protocol for a randomized controlled trial of a positive affect skills intervention
}

This article was published in the following Dove Press journal:

Open Access Journal of Clinical Trials

\section{Alice Verstaen' \\ Judith T Moskowitz ${ }^{2}$ \\ Karin E Snowberg' \\ Jennifer Merrilees ${ }^{3}$ \\ Glenna A Dowling'}

'Department of Physiological Nursing, University of California, San Francisco, San Francisco, CA, ${ }^{2}$ Department of Medical Social Sciences, Feinberg School of Medicine, Northwestern University, Chicago, IL, ${ }^{3}$ UCSF Memory and Aging Center, Weill Institute for Neurosciences, University of California, San Francisco, San Francisco, CA, USA
Correspondence: Glenna A Dowling Department of Physiological Nursing, University of California, San Francisco, 2 Koret Way N63I, San Francisco, CA 94143 , USA

Tel + I $415502779 \mid$

Email Glenna.Dowling@ucsf.edu
Abstract: Given the increasing number of family caregivers of persons with dementia (PWD) and the associated burden and detriments to both physical and mental health, interventions that aim to improve such outcomes are important. Studies are increasingly demonstrating the unique importance of positive emotions in coping with stress, independent from the impact of negative emotions. However, none have examined the benefits of interventions that target positive emotions for caregivers of individuals with a chronic and debilitating disease such as dementia. This paper presents the design and methods for a randomized controlled trial (RCT) of a positive affect skills intervention for family caregivers of PWD. The RCT is of a skillsbased intervention that seeks to increase the frequency and intensity of positive affect in order to improve outcomes such as well-being, coping, and physical and mental health. The skills are delivered by trained facilitators via five one-to-one Internet video sessions with family caregivers of persons diagnosed with dementia (eg, Alzheimer's disease, vascular dementia, unspecified). The control group is an emotion reporting/waitlist control. Follow-up assessments are conducted post-intervention and at 1, 3, and 6 months post-completion of the intervention. This study promises to be an important and needed step toward improving the lives of caregivers of PWD. Keywords: positive affect, dementia caregiving, coping, intervention, stress, RCT

\section{Introduction}

Dementia is a debilitating disease for the afflicted individuals as well as for the family members who care for them. As of 2017, 5.5 million people in the US alone live with a diagnosis of Alzheimer's disease, and this number, which does not include other causes of dementia, is projected to nearly double by $2050 .{ }^{1}$ Individuals with a diagnosis of dementia experience increased psychological, functional, and physical dependence as the disease progresses. Although the average life expectancy following the onset of the earliest symptoms is $8-11$ years (depending on the type of dementia), ${ }^{2}$ individuals can live as long as 20 years. As dementia progresses and severity increases, so does the time devoted to caregiving and the subsequent toll on caregivers. ${ }^{1,3-6}$ In addition, dementia caregiving in the US is estimated to cost approximately $\$ 9.3$ billion per year. ${ }^{7}$

A number of studies indicate that caregiving has negative physical and psychological effects. ${ }^{1,8}$ Caring for persons with dementia (PWD) can be a chronic stressor and burden as the PWD lose the ability to perform daily tasks and come to rely heavily on the caregiver(s) to meet their needs. In a nationwide poll of caregivers and 
non-caregivers, 59\% of dementia caregivers reported high levels of emotional and physical stress. ${ }^{1}$ This stress puts caregivers at greater risk than non-caregivers of developing a range of health issues. ${ }^{9-17}$ In addition to detriments in physical health, dementia caregivers can also experience higher levels of depression and reduced well-being. ${ }^{18-20}$ Despite powerful evidence of the negative impact of caregiving, it is important to highlight that the act of caregiving can also be a meaningful experience, ${ }^{21,22}$ and some caregivers exhibit a tremendous amount of resilience and positivity throughout the caregiving experience. ${ }^{23}$ Prior research has demonstrated that personality traits, coping styles, levels of social support, and relationship quality are linked to differences in caregiver outcomes and their overall caregiving experience. ${ }^{24-26}$ For some, caregiving can be a positive and meaningful experience while also contributing to the experience of stress and burden. ${ }^{27}$

Given the well-documented psychological and physical toll of caregiving, there is an important need for targeted interventions for dementia caregivers that seek to lessen burden and stress and increase positive emotions and experiences. To date, stress reduction, coping, educational, and psychosocial interventions for dementia caregivers have shown modest success. ${ }^{28,29}$ However, a growing body of research suggests that positive emotion is independently associated with beneficial outcomes, even when controlling for negative emotion, ${ }^{30-34}$ and indicates that interventions focused specifically on increasing positive emotion may decrease the deleterious impact of caregiving stress on the psychological and physical well-being of caregivers. Life Enhancing Activities for Family Caregivers (LEAF) is a randomized trial of a 5-week, evidence-based intervention designed to teach skills to boost positive affect and subsequently improve caregiver outcomes in physical and psychological functioning. This paper describes the theoretical and empirical underpinnings and design of a randomized controlled trial of the LEAF intervention for informal caregivers of PWD.

\section{Theoretical foundation of positive affect and stress}

There is a growing literature regarding the unique beneficial impact of positive affect on psychological adjustment and functioning, particularly during times of chronic stress. ${ }^{35-38}$ Revised Stress and Coping Theory ${ }^{21}$ suggests that positive reappraisal, goal-directed problem-solving, and other meaningfocused forms of coping lead to increased positive affect, thereby providing a psychological "time-out" from chronic stress and supporting continued practice of more effective coping strategies that reduce the negative effects of chronic stress. The Broaden and Build Model of positive emotion ${ }^{39}$ proposes a complementary pathway through which positive emotion may alleviate the experience of stress and improve coping. Broadening refers to the ability of positive emotion to help individuals see beyond the immediate stressor and leads to more creative alternative solutions. Building refers to the rebuilding of individual coping resources, such as social support and self-esteem that tend to be depleted during chronic stress. Fredrickson argues that repeated experiences of positive emotion build personal resources (eg, social support, physical health), which in turn buffer against the deleterious effects of stress. ${ }^{40-42}$ (Throughout this paper, the term "affect", referring to the experience of feeling emotion, will be utilized to describe the current study and prior research when appropriate, and "emotion" will be utilized when referencing prior research when appropriate.)

\section{Empirical findings for positive affect and stress}

As discussed, research in the realm of positive affect in healthy individuals suggests that positive affect, or specifically positive emotions, can have protective qualities and beneficial health outcomes. ${ }^{33,43-45}$ For example, Danner et al analyzed handwritten autobiographies written by 180 Catholic nuns prior to entering the convent. Positive emotional content in the written autobiographies was associated with lower risk of mortality over the next 60 years, even after controlling for negative emotion content, age, education, and measures of linguistic ability. ${ }^{30}$ Fredrickson et al examined how positive emotion was an important link between psychological resilience and posttraumatic growth following the terrorist attacks that occurred in the US on the 11th of September $2001 .^{40}$ This finding supports the idea that positive emotions help to rebuild resources that are depleted during stressful times, even acute stressors such as the 9/11 attacks.

In the domain of positive affect interventions, results of a recent meta-analysis suggest that interventions enhance well-being and reduce depressive symptoms. ${ }^{46}$ In a study examining the impact of positive affect training on individuals with recently diagnosed HIV, individuals in the positive affect intervention condition demonstrated lower use of antidepressants, fewer intrusive and avoidant thoughts, and higher levels of positive emotion at follow-up than individuals in the control condition. ${ }^{34}$

\section{Positive emotion and caregiving}

Among caregivers, positive affect predicts lower frailty over a 2-year follow-up ${ }^{47}$ and engagement in pleasant activities 
is associated with higher positive affect and lower negative affect. ${ }^{48}$ Positive caregiver resources such as optimism, resilience, and a sense of coherence are associated with lower levels of burden and higher quality of life. ${ }^{49,50}$ In the realm of dementia caregiving, few studies have examined the link between positive affect and psychological or physical health outcomes. However, one study found that caregivers who "focus on the positive" report greater well-being, ${ }^{51}$ suggesting that skills such as positive reappraisal may have beneficial effects on caregiver psychological outcomes. Caregiver interventions have primarily focused on education/ information, support, environmental/technical interventions, and caregiving-specific skill building. ${ }^{52,53}$ For example, interventions such as the "First you should get strong" program have demonstrated the beneficial impact of interventions that seek to increase caregiver knowledge about dementia on caregiver health. ${ }^{54}$ Although these types of interventions have been effective in reducing caregiver stress, burden, and depression, they tend to be time and resource intensive; hence, dissemination to a wider population is difficult. The intervention proposed in this article is unique in that it focuses on increasing positive affect, with the goal of reducing the negative psychological impact of caregiving.

\section{Methods}

The LEAF study (NCT01825681 on ClinicalTrials.gov) compares a five-session positive affect skills-building program to an emotion reporting/waitlist control group. Intervention sessions (LEAF sessions) are delivered one on one by trained facilitators via videoconference on study-supplied tablet computers. LEAF sessions follow a script to impart information about positive affect-building skills, and the facilitator discusses skills practice with participants individually, inviting them to use pertinent examples from their own lives to practice and develop each skill. Between the weekly sessions, participants complete short home practice assignments each day. Home practice is recorded in a workbook and sent back to the study coordinator when all sessions are complete. A sixth and final session is conducted to review the previous week's homework and to discuss strategies for long-term practice.

All participants are assessed at baseline, after the intervention, and at three follow-up time points: 1,3 , and 6 months post-intervention. Waitlist control subjects are assessed at baseline and also at a second baseline (Assessment 2), after an initial wait period of 6 weeks, equal to the length of the intervention. Figure 1 presents the participant flow diagram.

\section{Participants}

\section{Eligibility}

Each participant enrolled was the primary family caregiver of a person who had been 1) diagnosed with a degenerative dementia condition and 2) living with the caregiver or in his/ her own home, with the caregiver visiting often. Participants were English speaking and reading, and had reliable WiFi Internet at home or in another private location accessible to them. The study coordinator, who holds a Master's in counseling psychology, screened anyone who showed obvious signs of potential cognitive difficulty using the Telephone Instrument for Cognitive Status. ${ }^{55}$ All procedures were approved by the Institutional Review Board (UCSF IRB \#14-13236), and all participants provided informed consent.

\section{Study procedures}

\section{Recruitment and screening}

Participants were recruited via brochures in clinic waiting rooms, by word of mouth in caregiver support groups, both in-person and online, and by Internet postings on online bulletin boards, clinical trial matching sites, and Facebook. Interested caregivers were directed to the LEAF study website and asked to fill out a short contact survey, which included questions about their eligibility and their caregiving situation. The study coordinator then contacted them to set up a phone screening appointment.

During the phone screening appointment, the coordinator explained to interested caregivers that they would be taking part in a program to learn and practice new skills that aimed to reduce their level of stress. The program was delivered via videoconference on a tablet computer that we supplied to them, and participants were asked to complete short home practice activities and online surveys. The randomization process with the corresponding timelines of assessments was explained in detail. Willing participants were then sent a link to the online consent form.

\section{Consent, assessments, randomization, and setup}

After signing the online consent form, participants were sent an email that contained a link to their first assessment survey. As soon as the survey was completed, they were randomized and notified of their group assignment and next steps.

The study statistician generated a randomization table for two groups (intervention, control), population density category (Department of Defense: rural [1-999 persons per mi²], suburban $\left[1,000-3,000\right.$ persons per $\left.\mathrm{mi}^{2}\right]$, and urban $[>3,000$ persons per $\left.\mathrm{mi}^{2}\right]$ ), and gender (male, female). Randomization 


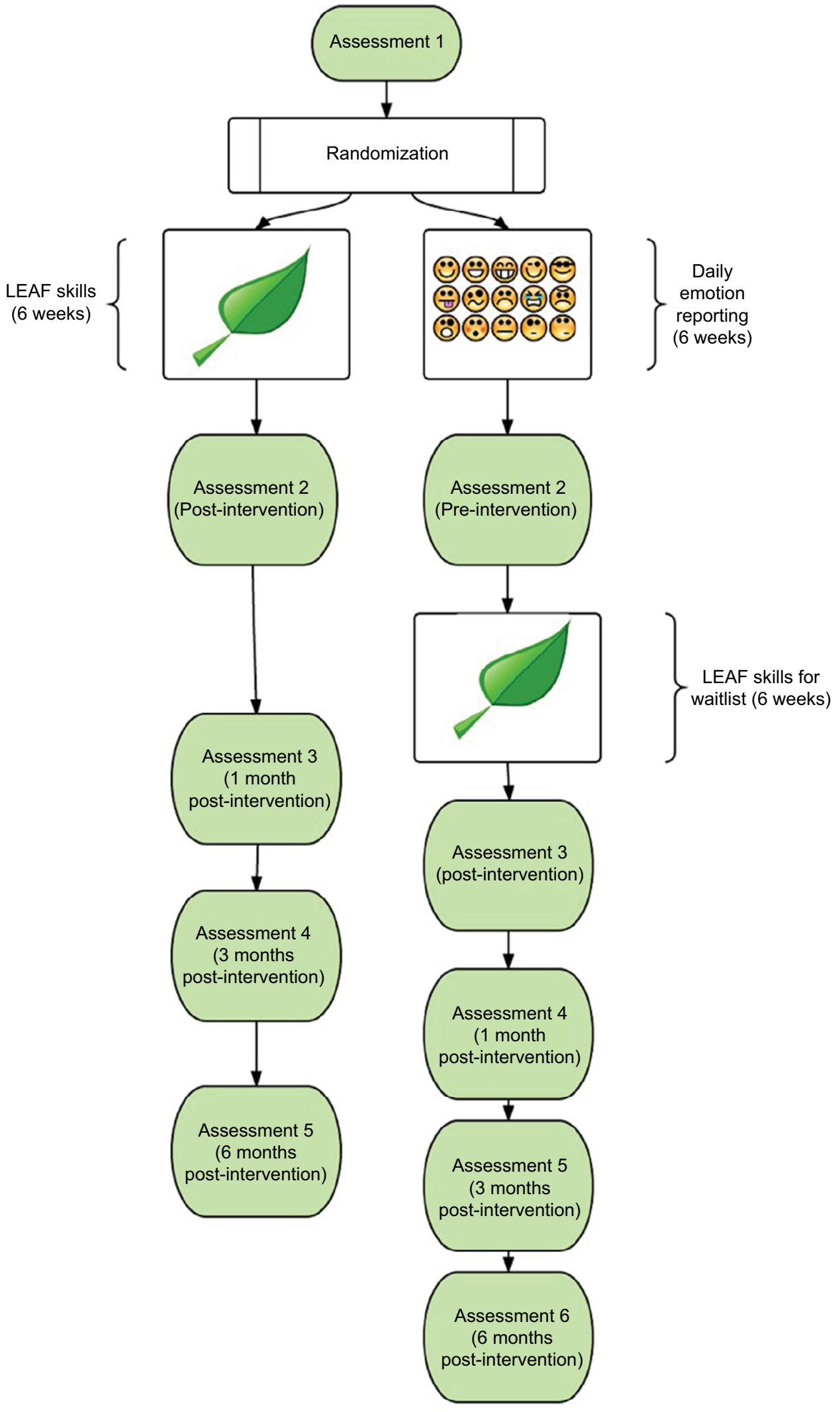

Figure I Participant flow.

Abbreviation: LEAF, Life Enhancing Activities for Family caregivers. 
within each category was in sets of four cases. Participants were automatically randomized after completing their baseline assessment via a FileMaker database that contained their demographic information and population classification.

\section{Size/power estimation}

The first two primary aims were used to determine the sample size for the study. The first is to test the effect of the intervention compared to a control group, and the second is to estimate the main effects of age and geography on psychological and coping outcomes. Given a sample size of 170 , assuming a two-sided alpha of 0.05 and a power of 0.80 , a constant correlation between the three assessments of 0.4 , and an overall attrition of $19 \%$, we will be able to detect a medium effect of 0.5 (Cohen's $d^{56}$ ). With these same assumptions, we would be able to detect the very large effect of 1.03 (Cohen's $d$ ) between the intervention and control groups with a sample of 42 (21 in each group). This effect size is based on our prior research, from which we estimated an effect size of 0.21 (partial eta-squared) on the measure of burden. Due to the importance of examining the main effect due to age on our outcomes for this population, we are powering the study for this second primary aim. Estimation was carried out with RMASS2. ${ }^{57}$

\section{LEAF intervention group}

Intervention group participants were contacted immediately and asked to confirm that they were ready to move forward and would be available to receive a package containing a tablet computer, a LEAF workbook, directions, and accessories. They were asked to give their availability for a 30-minute tablet setup appointment with the coordinator to test a videoconference meeting (WebEx) and schedule their LEAF sessions. As soon as they confirmed and gave appointment availability, the coordinator scheduled the setup appointment and shipped the tablet package to the participants.

Intervention group participants received emailed links to an emotion checklist survey (Differential Emotions Scale $[\mathrm{DES}]^{40}$ ) each evening that they were in the LEAF program. The emails were sent automatically starting the day of Session 1 and ending the day of Session 6, regardless of time spent in the program.

\section{Emotion reporting/waitlist control group}

Control group participants were contacted and notified that they would begin receiving a daily email with a link to the emotion checklist. They were to complete this survey daily for the next 6 weeks (the length of the skills intervention). After the completion of these 6 weeks, caregivers in the control group were notified and sent another assessment survey link (Assessment 2). Then, they were walked through the tablet setup and proceeded into the LEAF intervention sessions, identical to the intervention group (Figure 1). Waitlist control participants continued to receive daily links to the emotion checklist throughout setup and sessions, ending on the day of Session 6.

For both groups, follow-up assessment links were sent out within a week of the completion of Session 6, and then at 1,3 , and 6 months post-intervention. If a participant had not completed an assessment survey within 7 days of assignment, the coordinator sent him/her a reminder email.

\section{Attrition/retention}

To minimize attrition, the project director maintained an open line of communication with all participants, starting prior to informed consent, all the way through the last follow-up assessment. If contact was lost with a participant, the project director made several attempts to contact him/her by email and phone.

\section{Technology}

Using videoconference on tablet computers to communicate with study participants gave us the ability to easily include caregivers all over the country, including those in rural areas where resources are often scarce. This method enabled participants without their own computers to take part with minimal invasiveness and minimal setup time and cost. Videoconferencing also helped in building rapport between the participant and the facilitator.

Each participant, once randomized (intervention group) or once the second baseline completed (emotion reporting/ waitlist control group), was contacted and sent a package that contained study materials and a Samsung 8-inch tablet computer. The tablet had been previously set up by the study coordinator and included an anonymous Google account, WebEx app, 10-minute guided breath awareness .mp3 accessible by an audio player on the home screen of the tablet, and a simple timer app (for silent breath awareness practice, alternative to the guided audio track). Before scheduling LEAF sessions, the study coordinator had a tech setup meeting with participants individually to walk them through the steps of joining a WebEx meeting and to familiarize them with the other uses of the tablet.

The participants were invited to keep their tablet for their own personal use at the end of study participation, after all follow-up data had been collected. Participants who 
withdrew from the study early were given instructions and mailing supplies to return the tablet and study workbook to the study office.

\section{The LEAF intervention: skills}

The LEAF intervention consists of five sessions in which a facilitator teaches participants a series of eight behavioral and cognitive "skills" for increasing positive affect. The intervention has demonstrated feasibility, acceptability, and preliminary efficacy in pilot tests and randomized trials in a number of different samples ${ }^{34,58-62}$ including dementia caregivers. ${ }^{63}$ An important characteristic of successful positive affect interventions is match of the person to the activity.$^{64}$ It is likely that preferred and effective skills will differ across people, so having several options to choose from, as in this program, may increase the likelihood that the intervention, as a whole, will have an effect. We briefly review the rationale for inclusion of each of the skills here. Details on development of the positive affect skills intervention are published elsewhere. ${ }^{61,63,65}$ Table 1 provides an overview of the intervention sessions and home practice.

\section{Positive events and capitalizing}

Noticing enjoyable life events as they happen has been associated with increased positive emotion in general. Some types of therapy for depression ask the PWD to willfully schedule "pleasant events" in their days, ${ }^{66-68}$ and previous studies demonstrate that even during times of severe stress, noting and experiencing positive events can help individuals cope with the stress. ${ }^{21}$ We hypothesize that people under prolonged stress may intentionally create or seek out positive events, thus increasing positive affect and strengthening their ability to cope. The emotional effect of a positive event can be extended by telling someone about the event, writing it down, or even remembering the event later on. This can be thought of as capitalizing on the event, which strengthens the association between the event and the resulting positive affect. ${ }^{69}$

\section{Gratitude}

We define gratitude as a feeling of appreciation or thankfulness, expressed toward other people, or toward a religious or spiritual presence. The connection between noting what one is grateful for in a regimented and intentional way and

Table I Overview of the intervention sessions and home practice

\begin{tabular}{|c|c|c|c|}
\hline $\begin{array}{l}\text { Session } \\
\text { number }\end{array}$ & Skills & Goals of session & Home practice \\
\hline 1 & $\begin{array}{l}\text { Positive events, } \\
\text { capitalizing, gratitude }\end{array}$ & $\begin{array}{l}\text { Discuss what can constitute a positive } \\
\text { or meaningful event. What it means to } \\
\text { note, savor, and capitalize on positive } \\
\text { events. Discuss gratitude for positive } \\
\text { things in life }\end{array}$ & $\begin{array}{l}\text { Write down three things that went well each day and why they } \\
\text { went well. Begin a gratitude journal (writing one thing each day } \\
\text { you are grateful for) that will continue throughout the rest of the } \\
\text { intervention }\end{array}$ \\
\hline 2 & Mindfulness & $\begin{array}{l}\text { Teach the concepts of mindful } \\
\text { attention and nonjudgment }\end{array}$ & $\begin{array}{l}\text { I) Practice awareness of breathing and meditation for } 10 \text { minutes } \\
\text { daily, and 2) once a day, take time to enjoy something that you } \\
\text { usually hurry through - live in the moment doing one thing at a } \\
\text { time and pay attention to it. Participants will be encouraged to } \\
\text { continue the breathing exercise through the remaining weeks of } \\
\text { the intervention. Continue gratitude journal }\end{array}$ \\
\hline 3 & Positive reappraisal & $\begin{array}{l}\text { Discuss the meaning of positive } \\
\text { reappraisal and how to apply it to } \\
\text { everyday occurrences }\end{array}$ & $\begin{array}{l}\text { Each day think of one negative or stressful thing that happened. } \\
\text { Practice positive reappraisal - why it may not be as bad as initially } \\
\text { thought or something good that might come of it. Write about } \\
\text { your experience reappraising at the end of each day. Continue } \\
\text { gratitude journal and mindful breathing exercises }\end{array}$ \\
\hline 4 & $\begin{array}{l}\text { Personal strengths, } \\
\text { attainable goals }\end{array}$ & $\begin{array}{l}\text { Generate a list of personal strengths } \\
\text { that can be used in everyday life }\end{array}$ & $\begin{array}{l}\text { Set one attainable goal related to personal strengths each day and } \\
\text { strive to achieve it. Write about this experience at the end of the } \\
\text { day. Continue gratitude journal and mindful breathing exercises }\end{array}$ \\
\hline 5 & $\begin{array}{l}\text { Altruistic behaviors/ } \\
\text { acts of kindness - } \\
\text { doing for others }\end{array}$ & $\begin{array}{l}\text { Discuss the positive impact of doing } \\
\text { for others }\end{array}$ & $\begin{array}{l}\text { Practice a small act of kindness every day, and write about this } \\
\text { experience. Continue gratitude journal and mindful breathing } \\
\text { exercises }\end{array}$ \\
\hline 6 & Review of all skills & Plan how to continue utilizing the skills & \\
\hline
\end{tabular}

Notes: Monitoring the fidelity of intervention sessions during the course of the study included: I) revision and adaptation of detailed curriculum manuals for each of the sessions, 2) intensive training of facilitators, 3) incorporation of mock training sessions to ensure all facilitators met performance criteria for intervention session delivery before working with participants, and 4) audio and video recording of sessions for continued quality assurance. Throughout the study, each facilitator was periodically reviewed by the study data manager and checked to ensure that all main points of each session were covered. Whenever needed, facilitators were given detailed feedback and tips to improve content fidelity and/or quality of delivery. 
improved well-being has been well studied and documented. Several populations with serious mental or physical illness have shown fewer physical symptoms, greater positive and less negative affect, greater life satisfaction, and better sleep after keeping a regular gratitude practice..$^{70,71}$

\section{Mindfulness}

Mindfulness is defined as paying attention to one's experience (sensations, feelings, thoughts) in the present moment, while maintaining a nonjudgmental attitude toward that experience. ${ }^{72}$ Trait and state mindfulness have been correlated with higher levels of positive affect and lower levels of negative affect, and interventions that aim to increase mindfulness demonstrate increased positive affect. ${ }^{73,74}$

\section{Positive reappraisal}

Positive reappraisal of an event is a cognitive technique in which the event's significance is reinterpreted in a more positive way. For example, a stressful event can be reappraised as "not as bad as it could have been" or by finding a "silver lining" that came as a result of the event. Stress and coping theory states that an event is experienced as stressful in relation to the individual's appraisal, or interpretation, of the event. Positive reappraisal has been associated with increased positive affect. $^{21,75,76}$

\section{Focusing on personal strengths}

Recognizing and focusing on one's personal strengths is a form of self-affirmation that can increase positive affect. Research on self-affirmation and secondary appraisal has indicated that evaluating one's available resources to help cope with stress leads to a milder appraisal of the stressful event. ${ }^{77}$ Acknowledging one's positive qualities and strengths is associated with positive psychological and physical outcomes. ${ }^{78,79}$

\section{Attainable goals}

The perceptions of persons of the progress they make toward achieving their goals are associated with higher levels of positive affect and greater well-being. ${ }^{80,81}$ Pursuing attainable goals (shorter term, smaller goals vs. more distant, longer term goals) is related to subjective reports of greater wellbeing. One study examined an intervention for students to promote goal attainment, finding greater increases in positive emotion in the intervention group. ${ }^{82}$

\section{Acts of kindness}

Performing altruistic behaviors, or acts of kindness toward others, is associated with increased levels of positive emotion, lower risk of serious illness, and lower risk of mortality. ${ }^{83-86}$ We hypothesize that performing acts of kindness may increase positive affect by distracting ones from their own experience and their own stress, and it may increase selfesteem and feelings of self-efficacy and sense of control.

\section{Outcome measures}

\section{Psychological well-being}

\section{Positive and negative emotion}

A 20-item modified version of the DES is used to assess positive and negative emotion. The version used includes additional positive affect and positive affectivity items, scored to create total positive and total negative affect scores. In the baseline data for the present study, the modified DES shows acceptable reliability with the positive affect subscale $(\alpha=0.91)$ and the negative affect subscale $(\alpha=0.85)$.

\section{Stress}

The 10-item Perceived Stress Scale ${ }^{87}$ is used to measure how overloaded, unpredictable, and uncontrollable respondents perceive their lives to be. Scores range from 0 to 40 , and higher scores indicate a higher stress level.

\section{Burden}

The Zarit Burden Interview ${ }^{88}$ is used to assess perceived burden in caregivers. This measure's 22 items assess subjective feelings of the impact of caregiving on emotional and physical health, financial strain, and social functioning. Higher scores reflect greater burden.

\section{Strain}

Caregiver Strain Index (CSI) ${ }^{89}$ is used to assess perceived strain. The CSI is a 13-item measure of both objective and subjective elements of caregiver strain. Scoring includes dichotomous response choices consisting of "yes" if the item applies to the caregiver's situation and "no" if it does not. The number of "yes" answers is added to calculate the total score, which ranges from 0 to 13 . A score of 7 or higher has been shown to indicate clinically significant caregiver strain.

\section{Depressive mood}

Emotional Distress - Depression, Patient Reported Outcomes Measurement Information System Item Bank, v.1.0 $\left(\mathrm{PROMIS}^{90}\right.$ ) is used to assess depressive mood. Participants rate 28 items focused on depressive symptoms over the past 7 days. Each item is rated on a scale from Never to Always. Supported by the National Institutes for Health, PROMIS 
provides access to adult-reported measures of symptoms and aspects of health-related quality of life.

\section{Anxiety}

The NeuroQOL ${ }^{91}$ is used to assess anxiety. This measure contains 29 items assessing anxiety over the past 7 days. Each item is rated on a scale from Never to Always.

\section{Coping}

Participants completed the coping scale previously used by Dr. Moskowitz that combines the short Ways of Coping Scale ${ }^{92}$ items with a number of other measures hypothesized to be correlated with positive affect. ${ }^{93,94}$ The scale measures 23 forms of coping responses, such as escape avoidance, mastery of stress, problem-solving, emotional processing and expression, and positive reappraisal.

\section{Demographic measures}

In addition to collecting information regarding caregiver age, length of time as a caregiver, relationship to care recipient, sex, race/ethnicity, marital status, education, and contact information of the primary care provider, the following measures are collected to characterize the sample.

\section{Global health}

Global Health Scale, PROMIS v.1.0/1.1 $1^{90}$ is used to assess the study participants' perceptions of their health, quality of life, and abilities to carry out physical activities. The Global Health Scale contains 10 items that are rated on a scale of Excellent to Poor.

\section{Rating of dementia severity}

The Dementia Severity Rating Scale (DSRS) ${ }^{95,96}$ is used to characterize the level of functional abilities of the PWD being cared for by the study subjects. The DSRS collects information from the caregiver on impairment severity of the PWD in 12 functional and cognitive ability domains. The full range of dementia severity is assessed, from no impairment observed to extreme impairment observed in each category.

\section{Positive aspects of caregiving}

These are measured by Positive Aspects of Caregiving, an 11-item scale that identifies positive consequences of caregiving such as feeling more useful, feeling appreciated, and strengthening relationships with others. Higher scores indicate greater identification of the positives of being a caregiver. $^{97}$

\section{Planned analyses}

The primary outcomes examined in this study are positive affect, negative affect, stress, burden, depression, anxiety, and other mental and physical health outcomes (outlined in more detail above). Our first and primary aim is to test whether participants in the intervention group demonstrate significantly greater improvements in psychological outcomes and engagement in problem-focused and positive appraisal forms of coping, when compared to the waitlist participants. The second aim is to test the associations of age and geography with each outcome over time and whether these demographics moderate the effects of the intervention. The third aim is an extension of Aim 1, using additional assessments of outcomes to demonstrate the trajectories of the combined intervention and waitlist groups, once the latter completes the intervention.

Before testing hypotheses, we will examine the baseline characteristics of the intervention and waitlist groups, to ensure that variables of interests are evenly distributed between groups. Key variables of interest include age, gender, education, ethnicity, geographic location, length of time as caregivers, and relationship to the PWD. Status variables that differ across the two group assignments will be included in the analyses as covariates.

\section{Aim I}

The primary analysis is based on the intention-to-treat paradigm (ie, in primary analyses, all randomized subjects are analyzed based on their assigned group, regardless of their compliance with the intervention). To test the primary hypotheses that experimental subjects who participate in LEAF demonstrate significantly higher levels of positive affect and lower levels of negative affect, in addition to improvement in various psychological outcomes (eg, depression, physical health) compared to the waitlist control condition, we will conduct a multilevel regression analysis of the repeated measures. The dependent variables in these analyses are measured on two occasions (baseline and post-intervention for the experimental group and baseline and post-intervention for the control group). Group (experimental or waitlist control) is the between-subjects factor. This method allows for testing the main effects for time and group, and the cross-level interaction (the interaction of group by time). The interaction is most relevant because it tests whether changes in the dependent variables over time are the same for the two groups.

Before hypothesis tests are conducted, the distributional properties of the dependent variables will be checked for 
significant departure from normality, by conducting residual analyses with regressions (to determine the appropriateness of a linear regression model based on the raw data). Those that are normally distributed and whose residuals are randomly dispersed will be examined with multilevel general linear models, and those that are not normally distributed will be examined with multilevel generalized linear models. The use of multilevel models (also called multilevel regression and hierarchical linear models) has several advantages over traditional repeated measures analysis such as analysis of variance (eg, multilevel models enables the use of all available data on each subject, and are unaffected by missing data). ${ }^{98-100}$ Analyses will be conducted using the Restricted Maximum Likelihood approach in SPSS 19.

\section{Aim 2}

Multilevel regression models will be conducted to test the associations of age (in years) and geography (urban, suburban, and rural) with the change for each outcome over the two assessments. Further, the possibility that age and/or geography moderate the effects of the intervention will be tested with three-way interactions (eg, group by age by time).

\section{Aim 3}

Aim 3 analyses will utilize the post-intervention assessments (months 3, 6, and 10) across both groups. Such analyses will enable us to examine whether benefits from the intervention are maintained over time. Since the waitlist control group is administered the LEAF intervention after the intervention group finishes the intervention (about 6 weeks), the follow-ups collected are comparable across both study groups. The test of change for the two combined groups will therefore be able to determine the shape of the trajectory for study participants following the end of the intervention, and whether benefits to caregivers remain at the 1-, 3-, and 6-month follow-ups.

\section{Discussion}

There is a vast literature on the experiences of dementia caregivers, demonstrating that in combination with positive and rewarding experiences attained, caregivers exhibit higher levels of burden, stress, and reduced levels of well-being ${ }^{101}$ compared to non-caregivers. Detrimental impacts on physical health are also worse for caregivers than for non-caregivers and increase in severity the more hours of caregiving an individual engages in. ${ }^{10,13}$ As the number of PWD in the US, and in the world, increases, so does the number of individuals who are and will become familial caregivers. Hence, there is an important need for interventions that alleviate negative effects of caregiving and increase the frequency of positive experiences and positive affect.

Recent research has demonstrated the unique benefits of positive affect for both psychological and physical health. Intervention studies that seek to boost the experience of positive affect have demonstrated success at enhancing well-being and reducing depressive symptoms. ${ }^{46,102}$ A recent study of the positive affect intervention delivered in person to people newly diagnosed with HIV demonstrated that individuals in the intervention had significantly less use of antidepressants and fewer intrusive and avoidant thoughts over time compared to participants in an active control condition. In addition, intervention participants demonstrated higher levels of positive affect at the three post-intervention assessments, compared to the controls. ${ }^{34}$ Studies such as these demonstrate the potential for positive affect skills interventions to improve the aspects of well-being and mental health. The design and successful implementation of our study provides evidence that positive affect interventions designed for caregivers of PWD are feasible. Given the high levels of stress, burden, and depression in family caregivers of PWD, the present study is an important and meaningful step toward improving the lives of these caregivers.

\section{Acknowledgments}

The authors sincerely thank Erin Hubbard, Eva Shiu, and Stephanie Schuette for their outstanding contributions as LEAF program facilitators and Paul Cotten for program facilitation and custom database creation. Also, the authors specially thank Judy Mastick for critically reviewing the proposal and Michael Cohn, who developed an online application to facilitate daily data collection. Research reported in this publication was supported by the National Institute of Nursing Research of the National Institutes of Health under Award Number R01NR014435. The content is solely the responsibility of the authors and does not necessarily represent the official views of the National Institutes of Health.

\section{Disclosure}

The authors report no conflicts of interest in this work.

\section{References}

1. Alzheimer's Association. 2017 Alzheimer's disease facts and figures Alzheimers Dement. 2017;13:325-373.

2. Roberson ED, Hesse JH, Rose KD, et al. Frontotemporal dementia progresses to death faster than Alzheimer disease. Neurology 2005;65(5):719-725.

3. Etters L, Goodall D, Harrison BE. Caregiver burden among dementia patient caregivers: a review of the literature. J Am Acad Nurse Pract 2008;20(8):423-428 
4. Hurd MD, Martorell P, Delavande A, Mullen KJ, Langa KM. Monetary costs of dementia in the United States. $N$ Engl $J$ Med. 2013;368(14):1326-1334.

5. Schubert CC, Boustani M, Callahan CM, Perkins AJ, Hui S, Hendrie HC. Acute care utilization by dementia caregivers within urban primary care practices. J Gen Intern Med. 2008;23(11):1736-1740.

6. Zhu CW, Scarmeas N, Ornstein K, et al. Health-care use and cost in dementia caregivers: longitudinal results from the Predictors Caregiver Study. Alzheimers Dement. 2015;11(4):444-454.

7. Alzheimer's Association. 2014 Alzheimer's disease facts and figures. Alzheimers Dement. 2014;10(2):e47-e92.

8. Zarit SH, Zarit JM. Mental Disorders in Older Adults: Fundamentals of Assessment and Treatment. 2nd ed. New York, NY: Guilford Press; 2011.

9. Roepke SK, Allison MA, Von Känel R, et al. Relationship between chronic stress and carotid intima-media thickness (IMT) in elderly Alzheimer's disease caregivers. Stress. 2012;15(2):121-129.

10. Gouin JP, Glaser R, Malarkey WB, Beversdorf D, Kiecolt-Glaser J. Chronic stress, daily stressors, and circulating inflammatory markers. Health Psychol. 2012;31(2):264-268.

11. von Känel R, Mausbach BT, Dimsdale JE, et al. Effect of chronic dementia caregiving and major transitions in the caregiving situation on kidney function: a longitudinal study. Psychosom Med.2012;74(2): 214-220.

12. Mausbach BT, Chatillon E, Roepke SK, et al. A longitudinal analysis of the relations among stress, depressive symptoms, leisure satisfaction, and endothelial function in caregivers. Health Psychol. 2012;31(4):433-440.

13. Chatillon EA, Mausbach BT, Roepke SK, et al. Leisure activities, caregiving demands and catecholamine levels in dementia caregivers. Psychol Health. 2012;27(10):1134-1149.

14. Kiecolt-Glaser JK, Marucha PT, Malarkey WB, Mercado AM, Glaser R. Slowing of wound healing by psychological stress. Lancet. 1995;346(8984):1194-1196.

15. Kiecolt-Glaser JK, Dura JR, Speicher CE, Trask OJ, Glaser R. Spousal caregivers of dementia victims: longitudinal changes in immunity and health. Psychosom Med. 1991;53(4):345-362.

16. von Känel R, Dimsdale JE, Mills PJ, et al. Effect of Alzheimer caregiving stress and age on frailty markers interleukin-6, C-reactive protein, and D-dimer. J Gerontol A Biol Sci Med Sci. 2006;61(9):963-969.

17. Schulz R, Beach SR. Caregiving as a risk factor for mortality: the Caregiver Health Effects Study. JAMA. 1999;282(23):2215-2219.

18. Fisher GG, Franks MM, Plassman BL, et al. Caring for individuals with dementia and cognitive impairment, not dementia: findings from the aging, demographics, and memory study. JAm Geriatr Soc. 2011;59(3):488-494.

19. Pinquart M, Sörenson S. Differences between caregivers and noncaregivers in psychological health and physical health: a meta-analysis. Psychol Aging. 2003;18(2):250-267.

20. Epstein-Lubow G, Gaudiano B, Darling E, et al. Differences in depression severity in family caregivers of hospitalized individuals with dementia and family caregivers of outpatients with dementia. $\mathrm{Am} \mathrm{J}$ Geriatr Psychiatry. 2012;20(9):815-819.

21. Folkman S. Positive psychological states and coping with severe stress. Soc Sci Med. 1997;45(8):1207-1221.

22. Cohen CA, Colantonio A, Vernich L. Positive aspects of caregiving: rounding out the caregiver experience. Int $J$ Geriatr Psychiatry. 2002;17(2):184-188.

23. Harmell AL, Chattillion EA, Roepke SK, Mausbach BT. A review of the psychobiology of dementia caregiving: a focus on resilience factors. Curr Psychiatry Rep. 2011;13(3):219-224.

24. Hooker K, Monahan D, Shifren K, Hutchinson C. Mental and physical health of spouse caregivers: the role of personality. Psychol Aging. 1992;7(3):367-375.

25. Parks SH, Pilisuk M. Caregiver burden: gender and the psychological costs of caregiving. Am J Orthopsychiatry. 1991;61(4):1-9.
26. Daley RT, O'Connor MK, Shirk SD, Beard RL. "In this together" or "Going it alone": spousal dyad approaches to Alzheimer's. J Aging Stud. 2017;40:57-63.

27. Beach SR, Schulz R, Yee JL, Jackson S. Negative and positive health effects of caring for a disabled spouse: longitudinal findings from the Caregiver Health Effects Study. Psychol Aging. 2000;15(2):259-271.

28. Pinquart M, Sörensen S. Helping caregivers of persons with dementia: which interventions work and how large are their effects? Int Psychogeriatr. 2006;18(4):577-537.

29. Gilhooly KJ, Gilhooly ML, Sullivan MP, et al. A meta-review of stress, coping and interventions in dementia and dementia caregiving. BMC Geriatr. 2016;16:106.

30. Danner DD, Snowdon DA, Friesen WV. Positive emotions in early life and longevity: findings from the nun study. J Pers Soc Psychol. 2001;80(5):804-813.

31. Moskowitz JT. Positive affect predicts lower risk of AIDS mortality. Psychosom Med. 2003;65(4):620-626.

32. Blazer DG, Hybels CF. What symptoms of depression predict mortality in community-dwelling elders? J Am Geriatr Soc. 2004;52(12): 2052-2056.

33. Pressman SD, Cohen S. Does positive affect influence health? Psychol Bull. 2005;131(6):925-971.

34. Moskowitz JT, Carrico AW, Duncan LG, et al. Randomized controlled trial of a positive affect intervention for people newly diagnosed with HIV. J Consult Clin Psychol. 2017;85(5):409-423.

35. Moskowitz JT, Epel ES, Acree M. Positive affect uniquely predicts lower risk of mortality in people with diabetes. Health Psychol. 2008;27(1S):S73-S82.

36. Folkman S, Moskowitz JT. Positive affect and the other side of coping. Am Psychol. 2000;55(6):647-654.

37. Boehm JK, Kubzansky LD. The heart's content: the association between positive psychological well-being and cardiovascular health. Psychol Bull. 2012;138(4):655-691.

38. Boehm JK, Trudel-Fitzgerald C, Kivimaki M, Kubzansky LD. The prospective association between positive psychological well-being and diabetes. Health Psychol. 2015;34(10):1013-1021.

39. Fredrickson BL. What good are positive emotions? Rev Gen Psychol. 1998;2(3):300-319.

40. Fredrickson BL, Tugade MM, Waugh CE, Larkin GR. What good are positive emotions in crises? A prospective study of resilience and emotions following the terrorist attacks on the United States on September 11th, 2001. J Pers Soc Psychol. 2003;84(2):365-376.

41. Gable SL, Reis HT, Impett EA, Asher ER. What do you do when things go right? The intrapersonal and interpersonal benefits of sharing positive events. J Pers Soc Psychol. 2004;87(2):228-245.

42. Gable SL, Gonzaga GC, Strachman A. Will you be there for me when things go right? Supportive responses to positive event disclosures. $J$ Pers Soc Psychol. 2006;91(5):904-917.

43. Cohen S, Pressman SD. Positive affect and health. Curr Dir Psychol Sci. 2006;15(3):122-125.

44. Fredrickson BL. Cultivating positive emotions to optimize health and well-being. Prev Treat. 2000;3(1):1a.

45. Nelson SK, Kushlev K, Lyubomirsky S. The pains and pleasures of parenting: when, why, and how is parenthood associated with more or less well-being? Psychol Bull. 2014;140(3):846-895.

46. Sin NL, Lyubomirsky S. Enhancing well-being and alleviating depressive symptoms with positive psychology interventions: a practicefriendly meta-analysis. J Clin Psychol. 2009;65(5):467-487.

47. Park-Lee E, Fredman L, Hochberg M, Faulkner K. Positive affect and incidence of frailty in elderly women caregivers and noncaregivers: results of Caregiver-Study of Osteoporotic Fractures. $J$ Am Geriatr Soc. 2009;57(4):627-633.

48. Mausbach BT, Coon DW, Patterson TL, Grant I. Engagement in activities is associated with affective arousal in Alzheimer's caregivers: a preliminary examination of the temporal relations between activity and affect. Behav Ther. 2008;39(4):366-374. 
49. Fianco A, Sartori RD, Negri L, Lorini S, Valle G, Delle Fave A. The relationship between burden and well-being among caregivers of Italian people diagnosed with severe neuromotor and cognitive disorders. Res Dev Disabil. 2015;39:43-54.

50. Trapp SK, Perrin PB, Aggarwal R, et al. Personal strengths and health related quality of life in dementia caregivers from Latin America. Behav Neurol. 2015;2015:507196.

51. Borden W, Berlin S. Gender, coping, and psychological well-being in spouses of older adults with chronic dementia. Am J Orthopsychiatry 1990;60(4):603-610.

52. Schulz R, Burgio L, Burns R, et al. Resources for Enhancing Alzheimer's Caregiver Health (REACH): overview, site-specific outcomes, and future directions. Gerontologist. 2003;43(4):514-520.

53. Boots LM, de Vugt ME, van Knippenberg RJ, Kempen GI, Verhey FR. A systematic review of Internet-based supportive interventions for caregivers of patients with dementia. Int $J$ Geriatr Psychiatry. 2013;29(4):331-344.

54. Lök N, Bademli K. Pilot testing of the "First you should get stronger" program among caregivers of older adults with dementia. Arch Gerontol Geriatr. 2017;68:84-89.

55. Brandt J, Spencer M, Folstein M. The telephone interview for cognitive status. Neuropsychiatry Neuropsychol Behav Neurol. 1988;1(2):111-117.

56. Cohen J. Statistical Power Analysis for the Behavioral Sciences. Hillsdale, NJ: Lawrence Erlbaum Associates; 1988.

57. Hedeker D, Gibbons RD, Waternaux C. Sample size estimation for longitudinal designs with attrition: comparing time-related contrasts between two groups. J Educ Behav Stat. 1999;24(1):70-93.

58. Carrico AW, Gómez W, Siever MD, Discepola MV, Dilworth SE, Moskowitz JT. Pilot randomized controlled trial of an integrative intervention with methamphetamine-using men who have sex with men. Arch Sex Behav. 2015;44(7):1861-1867.

59. Cheung EO, Cohn MA, Dunn LB, et al. A randomized pilot trial of a positive affect skill intervention (lessons in linking affect and coping) for women with metastatic breast cancer. Psychooncology. 2017;26(12):2101-2108.

60. Cohn MA, Pietrucha ME, Saslow LR, Hult JR, Moskowitz JT. An online positive affect skills intervention reduces depression in adults with type 2 diabetes. J Posit Psychol. 2014;9(6):523-534.

61. Moskowitz JT, Hult JR, Duncan LG, et al. A positive affect intervention for people experiencing health-related stress: development and non-randomized pilot test. J Health Psychol. 2012;17(5):676-692.

62. Caponigro JM, Moran EK, Kring AM, Moskowitz JT. Awareness and coping with emotion in schizophrenia: acceptability, feasibility and case illustrations. Clin Psychol Psychother. 2014;21(4):371-380.

63. Dowling GA, Merrilees J, Mastick J, Chang VY, Hubbard E, Moskowitz JT. Life enhancing activities for family caregivers of people with frontotemporal dementia. Alzheimer Dis Assoc Disord. 2014;28(2):175-181.

64. Lyubomirsky S, King L, Diener E. The benefits of frequent positive affect: does happiness lead to success? Psychol Bull. 2005;131(6):803-855.

65. Moskowitz J, Carrico A, Cohn M, et al. Randomized controlled trial of a positive affect intervention to reduce stress in people newly diagnosed with HIV; protocol and design for the IRISS study. Open Access J Clin Trials. 2014;6:85-100.

66. Lewinsohn PM, Sullivan JM, Grosscup SJ. Changing reinforcing events: an approach to the treatment of depression. Psychotherapy. 1980;17(3):322-334.

67. Lewinsohn PM, Amenson CS. Some relations between pleasant and unpleasant mood-related events and depression. J Abnorm Psychol. 1978;87(6):644-654.

68. Lewinsohn PM, Clarke GN, Hoberman HM. The coping with depression course: review and future directions. Can J Behav Sci. 1989;21(4):470-493.

69. Langston CA. Capitalizing on and coping with daily-life events: expressive responses to positive events. J Pers Soc Psychol. 1994;67(6): 1112-1125.
70. Emmons RA, McCullough ME. Counting blessings versus burdens: an experimental investigation of gratitude and subjective well-being in daily life. J Pers Soc Psychol. 2003;84(2):377-389.

71. Emmons RA. Thanks!: How the New Science of Gratitude Can Make You Happier. New York, NY: Houghton Mifflin Harcourt; 2008.

72. Kabat Zinn J. Mindfulness-based interventions in context: past, present, and future. Clin Psychol Sci Pract. 2003;10(2):144-156.

73. Grossman P, Tiefenthaler-Gilmer U, Raysz A, Kesper U. Mindfulness training as an intervention for fibromyalgia: evidence of postintervention and 3-year follow-up benefits in well-being. Psychother Psychosom. 2007;76(4):226-233.

74. Shapiro SL, Brown KW, Biegel GM. Teaching self-care to caregivers: effects of mindfulness-based stress reduction on the mental health of therapists in training. Train Educ Prof Psychol. 2007;1(2): 105-115.

75. Carver CS, Scheier MF. Situational coping and coping dispositions in a stressful transaction. J Pers Soc Psychol. 1994;66(1):184-195.

76. Sears SR, Stanton AL, Danoff-Burg S. The yellow brick road and the emerald city: benefit finding, positive reappraisal coping and posttraumatic growth in women with early-stage breast cancer. Health Psychol. 2003;22(5):487-497.

77. Lazarus RS, Folkman S. Stress, Appraisal, and Coping. New York, NY: Springer Publishing Company; 1984.

78. Taylor SE, Lerner JS, Sherman DK, Sage RM, McDowell NK. Are self-enhancing cognitions associated with healthy or unhealthy biological profiles? J Pers Soc Psychol. 2003;85(4):605-615.

79. Taylor SE, Lobel M. Social comparison activity under threat: downward evaluation and upward contacts. Psychol Rev. 1989;96(4):569-575.

80. Emmons RA. Abstract versus concrete goals: personal striving level, physical illness, and psychological well-being. J Pers Soc Psychol. 1992;62(2):292-300.

81. Emmons RA. The dual nature of happiness: independence of positive and negative moods. Paper presented at: Annual Meeting of the American Psychological Association; August 22-26, 1986; Washington, DC.

82. Sheldon KM, Houser-Marko L. Self-concordance, goal attainment, and the pursuit of happiness: can there be an upward spiral? J Pers Soc Psychol. 2001;80(1):152-165.

83. Oman D, Thoresen CE, McMahon K. Volunteerism and mortality among the community-dwelling elderly. J Health Psychol. 1999; 4(3):301-316.

84. Musick MA, Wilson J. Volunteering and depression: the role of psychological and social resources in different age groups. Soc Sci Med. 2003;56(2):259-269.

85. Moen P, Dempster-McClain D, Williams RW Jr. Successful aging: a life-course perspective on women's multiple roles and health. Am J Sociol. 1992;97(6):1612-1638.

86. Dunn EW, Aknin LB, Norton MI. Spending money on others promotes happiness. Science. 2008;319(5870):1687-1688.

87. Cohen S. Perceived stress in a probability sample of the United States. In: Spacapan S, Oskamp S, editors. The Social Psychology of Health. Thousand Oaks, CA: Sage; 1988:31-67.

88. Zarit SH, Reever KE, Bach-Peterson J. Relatives of the impaired elderly: correlates of feelings of burden. Gerontologist. 1980;20(6):649-655.

89. Robinson BC. Validation of a Caregiver Strain Index. J Gerontol. 1983;38(3):344-348.

90. Cella D, Riley W, Stone A, et al; PROMIS Cooperative Group. The Patient-Reported Outcomes Measurement Information System (PROMIS) developed and tested its first wave of adult selfreported health outcome item banks: 2005-2008. J Clin Epidemiol. 2010;63(11):1179-1194.

91. Cella D, Lai JS, Nowinski CJ, et al. Neuro-QOL: brief measures of health-related quality of life for clinical research in neurology. Neurology. 2012;78(23):1860-1867.

92. Folkman S, Lazarus RS, Pimley S, Novacek J. Age differences in stress and coping processes. Psychol Aging. 1987;2(2):171-184.

93. Moskowitz JT, Hult JR, Bussolari C, Acree M. What works in coping with HIV? A meta-analysis with implications for coping with serious illness. Psychol Bull. 2009;135(1):121-141. 
94. Fitzell A, Pakenham KI. Application of a stress and coping model to positive and negative adjustment outcomes in colorectal cancer caregiving. Psychooncology. 2010;19(11):1171-1178.

95. Clark CM, Ewbank DC. Performance of the dementia severity rating scale: a caregiver questionnaire for rating severity in Alzheimer disease. Alzheimer Dis Assoc Disord. 1996;10(1):31-39.

96. Xie SX, Ewbank DC, Chittams J, Karlawish JHT, Arnold SE, Clark CM. Rate of decline in Alzheimer disease measured by a Dementia Severity Rating Scale. Alzheimer Dis Assoc Disord. 2009;23(3):268-274.

97. Boerner K, Schulz R, Horowitz A. Positive aspects of caregiving and adaptation to bereavement. Psychol Aging. 2004;19(4):668-675.

98. Singer JD, Willett JB. Applied Longitudinal Data Analysis: Modeling Change and Event Occurrence. New York, NY: Oxford University Press; 2003.
99. Gueorguieva R, Krystal JH. Move over ANOVA: progress in analyzing repeated-measures data and its reflection in papers published in the Archives of General Psychiatry. Arch Gen Psychiatry. 2004; 61(3):310-317.

100. Hox JJ. Multilevel Analysis: Techniques and Applications. New York, NY: Routledge; 2010.

101. Schulz R, Martire LM. Family caregiving of persons with dementia: prevalence, health effects, and support strategies. Am J Geriatr Psychiatry. 2004;12(3):240-249.

102. Bolier L, Haverman M, Westerhof GJ, Riper H, Smit F, Bohlmeijer E. Positive psychology interventions: a meta-analysis of randomized controlled studies. BMC Public Health. 2013;13(1):119.

\section{Publish your work in this journal}

The Open Access Journal of Clinical Trials is an international, peerreviewed, open access journal publishing original research, reports, editorials, reviews and commentaries on all aspects of clinical trial design, management, legal, ethical and regulatory issues, case record form design, data collection, quality assurance and data auditing methodologies. The manuscript management system is completely online and includes a very quick and fair peer-review system, which is all easy to use. Visit http://www.dovepress.com/testimonials.php to read real quotes from published authors. 